minute at five different points in the oven; if satisfactory, these tests are repeated with food in the oven. The L.E.P. Co.'s experience is that the most critical practical test of an oven is the baking of plate pies, and the next most critical the baking of bread.

\section{Thermionic Valves as Measuring Instruments}

THE thermionic valve has long been recognized as a useful tool in many branches of science and engineering; but few, with the exception of experimenters, have realized that it can be usefully applied for measurement purposes. Until quite recently, engineers have regarded the valve as being rather an unknown factor and so have been reluctant to rely on it when precision measurements are required. In a paper presented to the Institution of Electrical Engineers on January 6, by Dr. E. G. James, G. R. Polgreen and $\mathbf{G} . \mathbf{W}$. Warren, the principles are outlined of various kinds of valves for the measurement of alternating voltages (including 'slide-back', peak, grid-leak and anode-bend voltmeters) and of voltmeters and electrometers for direct voltages. Methods of measuring very small values of current and power are described. Although the uniformity existing between the characteristics of valves of the same type is not quite perfect, the modern valve gives a very stable performance during its life, more particularly under the operating conditions imposed in measuring devices. Of all valve-measuring devices, the valve voltmeter probably is the most widely used instrument, especially for high-frequency measurements. It is sensitive and it can be designed to absorb negligible power from the source. In normal instrument practice, current is measured either by its magnetic or by its heating effect, and voltage is measured by measuring the current through a known resistance. In the case of instruments employing valves, the converse procedure is adopted. Voltage is measured by its controlling action on the electron current in the valve, while current may be determined by measuring the voltage produced across a known resistance. A simple and inexpensive valve voltmeter can be made to operate from pocket lamp batteries. It makes a useful selfcontained instrument with the general advantage of very high impedance and wide frequency range. The paper is a communication from the Research and Engineering staffs of the General Electric Co., Ltd., the M.O. Valve Co., Itd., at Wembley and the works of the Salford Instrument Co.

\section{Progress of Medical Psychology}

IN an address at a public luncheon arranged by the National Institute of Industrial Psychology on January 18, Dr. J. R. Rees, medical director of the Tavistock Clinic, said that this century has seen very great progress in both the science and the art of psychological medicine. Moreover, in the treatment of neurosis and nervous breakdown and in medicine as a whole, the introduction of the principles of medical psychology in the last few years has brought about a greater change than anything else in medicine. In the basic understanding of the processes of mental disease, much is owed of course to Freud and his followers, but the work of Jung, McDougall, Adler, Rivers and Hadfield - to mention only a fewhas been of an outstanding quality. The medical student can now be taught to understand the human beings with whom he has to deal without the use of any technical jargon and without any exclusive reference to a particular school of thought in psychology. In the actual treatment of the neuroses we are making steady advance. There is evidence from the careful follow-up work which has been done, first of all at the Tavistock Clinic and then at the Cassel Hospital at Penshurst, that approximately 50 per cent of the patients treated, irrespective of the particular method, seem to be permanently relieved and socially adjusted. That is a very satisfactory figure in comparison with the figures for other diseases. More important perhaps than the provision of treatment for the definite neuroses is the fact that through recent research we are coming to realize that many of the illnesses which have always been supposed to be mainly physical, have in fact a very large emotional factor in their causation. Psychological medicine is now coming into its own place in the system of medicine and is showing itself to have the closest possible relation to the problems of general medicine. The General Medical Council has now insisted that medical psychology should become part of the regular training of every medical student.

\section{Flora's League}

Botanists, nature-lovers and those who are concerned for the conservation of the native British flora will be interested to know that it has been decided to continue the activities of Flora's League, the national society for the preservation of wild flowers, trees and ferns, as a memorial to its founder, the late Sir Maurice Abbot-Anderson. Sir Maurice, a distinguished physician, founded the society in 1925 and was its president up to his death, when it had a following of more than twenty thousand members and a wide infuence through the public and school lectures it organized as propaganda for the preservation of the British flora from vandalism and unscientific collecting. Lady Abbot-Anderson has undertaken to carry on her husband's work as president of the League, which is closely associated with the Council for the Preservation of Rural England, the office of which it shares, and an appeal is being made for a fund to continue this work. In a statement on its policy, the League clearly refutes any suggestion of mere sentimentality or crankiness in its methods, for it points out: "There are inevitable economic influences at work which mitigate against the preservation of our wild flora, and with which we cannot quarrel. Building, road-making, drainage, quarrying and the like, must, in the ordinary course of things, proceed. Methods of transport also are more easily available, and bring enormous enjoyment, as well as increased health, to the population". A by-law against the uprooting of any wild plants from roadsides and places to which the public has access, without authoritative 
permission or a special permit for scientific purposes, is one of the chief aims of the League, and this has already been adopted by fifty-two counties and subcounties in England and Wales. From 1925, the whole of the expenses were met by the founder.

\section{Mathematical Films}

IN connexion with the note in NATURE of December 31, p. 1151, Mr. Stefan Bergmann writes to point out how films might be used to illustrate the theory of functions of two complex variables. Each complex variable may be represented as a point in a plane, requiring two dimensions, so two such variables require four dimensions. We may obtain these by taking three dimensions in space and one in time, in fact by making a film showing a solid body the dimensions of which vary with the time. Full details were given by Mr. Bergmann some years ago ( $J$. deutsch. Mathematiker Verein., 42, 238 ; 1932-33), but so far as we are aware no such films appear in current lists of those available for sale or hire.

\section{Nutrition and Local Government}

THE Children's Minimum Council, 72 Horseferry Road, London, S.W.1, has issued a pamphlet entitled "Nutrition and Local Government-What Your Isocal Authority Can Do" (by Marjorie E. Green. Price 3d.). Although changes in legislation are still needed to ensure that no child shall suffer from malnutrition through the poverty of its parents, there are two Acts of Parliament, the Public Health Act of 1936 and the Education Act of 1921, which enable local authorities to provide supplementary nourishment, and this pamphlet sets out clearly what each local authority can do in its own area to solve this problem of child malnutrition.

\section{Rheumatism Research in Naval Training Centres}

THE Empire Rheumatism Council, in co-operation with the Admiralty, has set up a research foundation to investigate rheumatic disease in the training establishments of the Royal Navy. The research advisory committee has appointed a sub-committee consisting of Lord Horder, Sir William Willeox, Prof. George Hadfield, Dr. Mervyn Gordon and Dr. W. S. C. Copeman to supervise the work. Dr. C. A. Green, of the Bacteriological Department of the University of Edinburgh, is to take direct charge of the Foundation, and the Sir Halley Stewart Trust has appointed him to a research fellowship for three years for this task.

\section{National Nutrition Conference}

THE British Medical Association has decided to call a national conference on nutrition in its wider aspects-that is, in relation to national, including agricultural, policy-which will last three days, the dates provisionally selected being April 27-29. In addition to medical men, the conference will be representative of agricultural producers, home and over-seas, as well as of industry and education. The conference will take as its starting-point the recognized food needs of the individual, if health is to be maintained. Questions to be considered include : How far are these needs satisfied in Great Britain at the present time? What increases are required in the production of particular foodstuffs, either at home or in the Empire, to fill the gap? How can the necessary increases in consumption be best secured-through a system of family allowances; education, including propaganda; or otherwise?

\section{Micro-Methods for Medical Practitioners and Biologists}

IN conjunction with the Institute of Scientific Mieroscopy and Applied Opties of the University of Jena, Messrs. Carl Zeiss, Jena, are organizing a course of microscopy, microphotography, micro-cinematography, micromanipulation, Iuminescence microscopy, also absolute colorimetry, interferometry and spectral analysis, with particular reference to their significance in medicine and biology, to be held in Jena during March 27-April 1. During the lectures provided in the programme there will be talks by eminent authorities on optical methods. Of particular note is the fact that members will be offered the opportunity of widening their experience in the use of the apparatus and above all of trying out in practice the methods referred to during the lectures. Demonstrators and specialists will be available to answer all questions arising during the practical work in the laboratory. Further particulars and detailed programme can be obtained, in England, from Carl Zeiss (London), Istd., Mortimer House, Mortimer Street, W.1.

\section{New Comet and Super-nova}

A TELEGRAM from Copenhagen reports that Peltier, at Delphos, Ohio, discovered a comet on Jan. 20.000 U.T., its approximate position being R.A. $21^{\text {h }} 20 \cdot 0^{\mathrm{m}}$, Dec. $+28^{\circ} 0^{\prime}$, and its magnitude 8 . A later telegram states that Beljawsky saw the comet several hours earlier and found that its daily motion was $+5^{\mathrm{m}} 48^{\mathrm{s}}$ in R.A. and $-0^{\circ} 13^{\prime}$ in declina. tion. He gave the magnitude as 8 and estimated the tail to be about $1^{\circ}$. Other observations must have been available to Karstedt, who has computed the orbit and ephemeris given below ; as the observations are very rough, the orbit cannot be regarded as more than provisional.

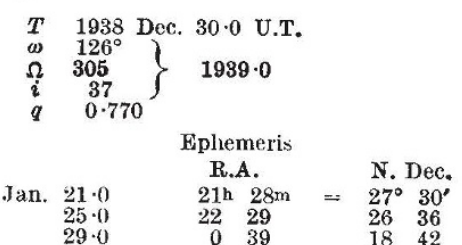

Zwicky reports a super-nova, mag. 17 on January I4, 12.5 on January 20 . It is $0 \cdot 6^{\prime}$ north-west of the nucleus of N.G.C. 4636.

\section{The Night Sky in February}

The moon is full on February 4 at $7 \cdot 9^{\text {h }}$ U.T. and new on February 19 at $8 \cdot 5^{\mathrm{h}}$. Lunar conjunctions with the planets occur as follows : with Mars on February 12 at $13^{\mathrm{h}}$; with Venus on February 15 at $3^{\mathrm{h}}$; with 